\begin{abstract}
Ability to Receive Compassion From Others Buffers the Depressogenic Effect of Self-Criticism: A Cross-Cultural Multi-Study Analysis
\end{abstract}

Nicola Hermanto, David C. Zuroff, and Daniel C. Kopala-Sibley McGill University

\author{
Allison C. Kelly \\ University of Waterloo \\ Marcela Matos \\ University of Coimbra \\ Paul Gilbert \\ Kingsway Hospital \\ Richard Koestner \\ McGill University
}

\begin{abstract}
Author Note
Nicola Hermanto, Department of Psychology, McGill University; David C. Zuroff, Department of Psychology, McGill University; Daniel C. Kopala-Sibley, Department of Psychology, McGill University; Marcela Matos, Cognitive-Behavioural Research Centre, University of Coimbra; Paul Gilbert, Mental Health Research Unit, Kingsway Hospital; Richard Koestner, Department of Psychology, McGill University.

Daniel C. Kopala-Sibley is now at the Department of Psychology, Stony Brook University.

Correspondence concerning this article should be addressed to Nicola Hermanto, Department of Psychology, McGill University, 1205 Dr. Penfield Avenue, Montreal, QC H3A 1B1, Canada. Email: nicola.hermanto@mail.mcgill.ca
\end{abstract}




\begin{abstract}
Self-criticism has been shown to be a vulnerability factor that can lead to and maintain depression. We examined the moderating effect of fear of receiving compassion from others on the positive association between self-criticism and depression. Self-report measures were administered to four separate samples (total $N=701$ ) varying in age (students and community adults) and cultural context (Canada, England, and Portugal). Two different measures of selfcriticism and of depression were administered to investigate the generalizability of results. Selfcriticism, depression, and fear of compassion from others were positively related to one another in all samples. As predicted, fear of compassion from others exerted a moderating effect on the relationship between self-criticism and depression. Low fear of compassion from others weakened the depressogenic effect of self-criticism, while high fear of compassion from others exacerbated the effect. Thus, a self-critic's ability to be open and responsive to care and support from others protected against depression. The aggregate moderating effect across the four studies was of medium size $(d+=.53)$ and highly significant, indicating a robust phenomenon. Implications for working with self-critical depressed patients are discussed.
\end{abstract}

Keywords: Self-criticism, depression, fear of compassion, attachment 


\section{Ability to Receive Compassion From Others Buffers the \\ Depressogenic Effect of Self-Criticism: A Cross-Cultural Multi-Study Analysis}

Excessive self-criticism is a personality vulnerability factor that can lead to and maintain various psychological difficulties, including depression (Blatt, 2004; Blatt \& Zuroff, 1992; Gilbert \& Irons, 2005). Because self-criticism is generally viewed as a stable and relatively intractable personality style, it is important to study moderating factors to identify processes that may buffer against its depressogenic effects. Using a multi-study approach with samples varying in age and cultural context, this article examines the moderating effect of fear of receiving compassion from others on the positive association between self-criticism and depression.

\section{Self-Criticism and Depression}

According to Blatt (1974), depression can arise from one of two dysfunctional personality configurations, which constitute two distinct types of vulnerability - the introjective (self-critical) personality and the anaclitic (dependent) personality. The self-critical personality is characterized by intense feelings of inferiority, guilt, worthlessness, and failure to live up to one's standards (Blatt, D'Afflitti, \& Quinlan, 1976). Individuals with high levels of self-criticism engage in relentless self-scrutiny and harsh self-evaluations in their attempts to avoid failure and meet their high personal ideals. They have extreme fears of disapproval, criticism, and rejection in the eyes of others. Gilbert, Clarke, Hempel, Miles, and Irons (2004) have suggested that selfcriticism can vary in function and form. Self-criticism can arise from efforts to improve the self and maintain strict standards or, alternatively, from efforts to punish, denigrate, and destroy the self.

Various theoretical perspectives view early experiences with caregivers as a key factor in shaping an individual's development. Theories from the domains of attachment (Bowlby, 
1969/1982), psychoanalysis (e.g., Blatt, 1974; Kernberg, 1976), and interpersonal relationships (e.g., Baldwin, 1992) converge on the notion that people who are raised in controlling and critical environments develop a harsh, critical way of relating to themselves. Indeed, research provides support for the hypothesized developmental origins of self-criticism (for a review, see Kopala-Sibley \& Zuroff, 2014). Self-criticism has been posited to pose a vulnerability to depression through various mechanisms, including but not limited to, negative mental representations (cognitive-affective schemas) of self and others, impairments in affect regulation, a pessimistic cognitive style, unsupportive social relationships; and feeling defeated and low in social rank (for reviews, see Blatt, 2004; Blatt \& Homann, 1992; Gilbert, 2006; Gilbert \& Irons, 2005; Zuroff, Santor, \& Mongrain, 2005). Overall, people who internalize a hostile and critical way of relating to themselves are more vulnerable to developing depression.

Extensive empirical evidence has demonstrated that self-criticism is highly correlated with depression in both non-clinical and clinical populations (for reviews, see Blatt \& Zuroff, 1992; Shahar, 2015; Zuroff, Mongrain, \& Santor, 2004). Furthermore, self-critical individuals face poorer treatment outcomes for depression. Self-criticism at baseline predicts poorer outcomes across treatment modalities, including cognitive-behavioural therapy, interpersonal therapy, and antidepressant medication (Blatt, Quinlan, Pilkonis, \& Shea, 1995; Blatt \& Zuroff, 2005; Rector, Bagby, Segal, Joffe, \& Levitt, 2000). Self-criticism has also been shown to have detrimental effects beyond the course of treatment. In a group of recovered depressed patients, for example, self-criticism predicted an increased vulnerability to relapse following treatment (Teasdale \& Cox, 2001). 


\section{Fear of Receiving Compassion and Depression}

Fear of compassion involves discomfort or difficulty receiving care, kindness, and support from others during times of distress (Gilbert, McEwan, Matos, \& Rivis, 2011). People may fear compassion from others for several reasons. Being the recipient of compassion may be an unfamiliar experience. It may revive painful childhood memories of not receiving the care and kindness one desperately needed. Receiving compassion may be seen as a sign of weakness and a confirmation of one's negative self-image. Some individuals may feel underserving of compassion or fear becoming dependent on others who may not be available or genuinely willing to provide care (Gilbert, 2009; Gilbert \& Procter, 2006). Evidence suggests that the ability to be open and responsive to compassion and support from others provides a protective factor against depression. For example, the lack of an intimate, supportive relationship has been shown to be an antecedent to depression (Hirschfeld \& Cross, 1983), while having more numerous and more supportive social resources can improve post-treatment functioning and prevent depressive relapse (Billings \& Moos, 1985; George, Blazer, Hughes, \& Fowler, 1989). Moreover, individuals who perceive higher levels of social support are less susceptible to the impact of stress on depression than those who perceive lower levels of support (Wang, Cai, Qian, \& Peng, 2014).

\section{Self-Criticism and Fear of Receiving Compassion}

Self-criticism has been shown to be correlated with fear of compassion. In self-report studies of students (Gilbert et al., 2012; Gilbert et al., 2011) and depressed patients (Gilbert, McEwan, Catarino, \& Baião, 2014), those with high levels of self-criticism reported higher fear of receiving compassion from others. After undergoing a compassionate imagery exercise, selfcritics exhibited physiological responses that are indicative of threat (i.e., increased heart rate 
variability and reduced cortisol) (Rockliff, Gilbert, McEwan, Lightman, \& Glover, 2008). Selfcritical individuals have a motivational orientation focused on achievement at the expense of interpersonal strivings, which diminishes their opportunities to have affiliative and intimate relationships with others (Mongrain \& Zuroff, 1995). Self-critics are also focused on maintaining a positive self-image and gaining approval from others rather than revealing their weaknesses (Mongrain \& Zuroff, 1995). Not surprisingly, self-criticism is associated with a fearful avoidant attachment style suggesting that self-critics fear rejection and criticism (Zuroff \& Fitzpatrick, 1995). As a result, highly self-critical individuals make fewer requests for social support and perceive less support than what is available to them (Mongrain, 1998). A self-critic's perception of low support, in turn, contributes to their distress over time (Dunkley, Zuroff, \& Blankstein, 2003; Priel \& Shahar, 2000).

\section{Fear of Compassion as a Moderator of Self-Criticism and Depression}

Drawing on affective neuroscience and evolutionary principles, Gilbert (2005) suggested that psychopathology can be conceptualized using a tripartite model of affect regulation. In this model, there are three interacting systems evolved to attune to signals of threat, resources/incentives, and affiliation/soothing, which respectively trigger negative affect, higharousal positive affect, and feeling socially safe with others. Psychopathology, including depression, is theorized to stem from an imbalance of systems, particularly an over-activation of the threat system and an under-activation of the affiliation/soothing system (Gilbert, 2005).

The developmental history of self-critics is characterized by criticism and a lack of affection from important others (Kopala-Sibley \& Zuroff, 2014), likely leading to the maturation of an over-developed threat system. Indeed, the relationship between self-criticism and negative affect has been well-documented (e.g., Mongrain \& Zuroff, 1995). Self-criticism has also been 
viewed as an ongoing internal form of hostility and coldness, even if in the moment there are no such external sources. For example, Whelton and Greenberg (2005) asked participants to engage in a two-chair exercise, in which they were first asked to criticize themselves and then switch chairs and respond to the self-criticism. Highly self-critical individuals showed more contempt and disgust when delivering their self-criticism, and exhibited more submissive and shamed postures in response. Therefore, self-critics chronically activate an over-developed threat system and experience high levels of negative affect, rendering them vulnerable to depression.

The affiliation/soothing system is attuned to signals of support and care in relationships with others (Gilbert, 2005). Individuals who are highly fearful of receiving compassion are likely cut off from receiving signals of feeling socially safe and secure. Self-critical individuals tend to fear receiving compassion; therefore, it is not surprising that they reported low mean levels of social safeness in a daily diary investigation (Kelly, Zuroff, Leybman, \& Gilbert, 2012). However, among those self-critics who are open to receiving care and support in their relationships, the resulting activation of the affiliation/soothing system would serve to downregulate the threat system. Thus, low fear of compassion from others may buffer the depressogenic effect of self-criticism, while high fear of compassion from others may strengthen the effect.

\section{Present Study}

The primary objective of the study was to examine the relationships among self-criticism, fear of compassion from others, and depression, and to test the moderating effect of fear of compassion on the association between self-criticism and depression. Consistent with prior findings, we hypothesized that self-criticism, fear of compassion from others, and depression would be positively associated with one another. Additionally, we expected an interaction 
between self-criticism and fear of compassion from others in predicting depression. That is, selfcriticism and depression would be more strongly associated in individuals with high fear of compassion from others and more weakly associated in those with low fear of compassion. To examine the robustness of effects, we tested our hypotheses using a multi-study approach comprising of four separate samples that varied in age (students and community adults) and cultural context (Canada, England, and Portugal), as well as two different measures of selfcriticism and depression.

\section{Study 1 (University Students from Montreal, Canada)}

\section{Method}

Participants and procedure. Participants were 64 undergraduate students (55 women, 9 men) attending a large university in Montreal, Canada ranging in age from 18 to 23 years old ( $M$ $=19.91, S D=1.50)$. Participants were primarily of Caucasian background $(62.0 \%)$, followed by Chinese (17.2\%), Southeast Asian (6.9\%), South Asian (5.2\%), West Asian (3.5\%), Arab (3.5\%), and Latin American (1.7\%). The sample was recruited through advertisements in the psychology research participant pool, university classifieds, and Craigslist. The study was advertised as a study of personality, mood, and interpersonal relationships. Participants received \$15 compensation or credit towards a course in undergraduate psychology. Participants completed a series of self-report measures online.

\section{Measures}

Fear of compassion from others. The Fears of Compassion Scales (FOCS; Gilbert et al., 2011) is a set of three subscales assessing fear of receiving compassion from others, as well as fear of expressing compassion towards others and fear of expressing compassion towards oneself. The FOCS is rated on a 5-point Likert scale ranging from 0 (don't agree at all) to 4 
(completely agree). The present study was concerned only with the subscale assessing fear of receiving compassion from others (e.g., "Feelings of kindness from others are somehow frightening" and "If I think someone is being kind and caring towards me, I put up a barrier"). The original subscale has 13 items but we administered only the five items with the highest factor loadings (Gilbert et al., 2011) to assess fear of compassion from others. In the present study, the subscale demonstrated good internal consistency with Cronbach's alpha of .84.

Self-criticism. Trait self-criticism was assessed using two measures: (a) the Inadequate Self subscale of the Forms of Self-Criticism/Self-Reassuring Scale (FSCRS; Gilbert et al., 2004) and (b) the Self-Criticism scale of the Depressive Experiences Questionnaire (DEQ; Blatt et al., 1976).

The FSCRS is a 22-item scale that assesses thoughts and feelings about the self in the context of a perceived failure. Two subscales assess forms of self-criticism (Inadequate Self which focuses on personal inadequacies, and Hated Self which focuses on the desire to hurt and derogate oneself) and one subscale measures capacities to be kind and reassuring to oneself (Reassured Self). The FSCRS is rated on a 5-point Likert scale ranging from 0 (not at all like me) to 4 (extremely like me). The two self-criticism subscales are considered to be differentially related to psychopathology, with the Hated Self facet representing a more pathological form associated with self-harm and more severe clinical symptoms (Gilbert et al., 2010). The two subscales have also demonstrated a different distribution of responses, with the Hated Self subscale showing a floor effect in non-clinical populations (Gilbert et al., 2012; Longe et al., 2010). Therefore, only the Inadequate Self subscale (e.g., "There is a part of me that feels I am not good enough" and "I am easily disappointed with myself") was retained for this study given 
its robust relationship with depression and full range of responses in non-clinical samples. The Inadequate Self subscale has 9 items. Cronbach's alpha in our study was .90.

The DEQ is a 66-item questionnaire that assesses two depressive personality dimensions, self-criticism and dependency (Blatt et al., 1976). Participants rated the extent to which they identify with a series of personal characteristics using a 7-point Likert scale ranging from 1 (strongly disagree) to 7 (strongly agree). The present study was concerned with the self-criticism factor only. All the DEQ items contribute to the self-criticism score, but each item is weighted using factor scoring coefficients derived from the original standardization sample (Blatt et al., 1976). High-loading items for this factor include "I often find that I don't live up to my own standards or ideals" and "If I fail to live up to expectations, I feel unworthy". Cronbach's alpha in our study was .73.

Depressive symptoms. Depressive symptoms were assessed with the Beck Depression Inventory-II (BDI-II; Beck, Steer, \& Brown, 1996). The BDI-II is a widely used 21-item measure of the severity of depressive symptoms in late adolescents and adults. Items are rated on a 4-point Likert scale ranging from 0 (symptom is not present) to 3 (severe symptom manifestation). The BDI-II has strong psychometric properties (Beck et al, 1996; Steer, Ball, Ranieri, \& Beck, 1997). In the current study, Cronbach's alpha was .94.

\section{Results}

\section{Descriptive Statistics and Correlations}

Descriptive statistics and correlations are presented in Table 1. Consistent with hypotheses, self-criticism, fear of compassion from others, and depression were positively correlated. The zero-order correlation between DEQ self-criticism and depression in this sample has been previously reported (Kopala-Sibley, Zuroff, Hermanto, \& Joyal-Desmarais, 2015). Self- 
criticism assessed using the Inadequate Self subscale of the FSCRS was moderately positively correlated with self-criticism assessed using the DEQ. Results using both measures of selfcriticism will be presented.

Table 1. Correlations and descriptive statistics for variables in Study 1 - University students from Montreal, Canada $(N=64)$

\begin{tabular}{|c|c|c|c|c|}
\hline & $\begin{array}{c}\text { Self- } \\
\text { Criticism (IS) }\end{array}$ & $\begin{array}{c}\text { Fear of Compassion } \\
\text { From Others }\end{array}$ & $\begin{array}{l}\text { Depression } \\
\text { (BDI-II) }\end{array}$ & $\begin{array}{l}\text { Self-Criticism } \\
\text { (DEQ) }\end{array}$ \\
\hline Self-Criticism (IS) & 1 & $.46^{*}$ & $.63 *$ & $.75^{*}$ \\
\hline $\begin{array}{l}\text { Fear of Compassion } \\
\text { From Others }\end{array}$ & & 1 & $.58^{*}$ & $.54 *$ \\
\hline $\begin{array}{l}\text { Depression (BDI-II) } \\
\text { Self-Criticism (DEQ) }\end{array}$ & & & 1 & $\begin{array}{r}.55^{*} \\
1\end{array}$ \\
\hline Mean & 17.27 & 4.97 & 10.21 & 0.14 \\
\hline SD & 8.30 & 3.83 & 10.33 & 0.95 \\
\hline
\end{tabular}

Note. IS = Inadequate Self. BDI-II = Beck Depression Inventory-II. DEQ = Depressive Experiences Questionnaire. Fear of Compassion From Others score is derived from a shortened 5-item version of the original scale.

$* p<.001$.

\section{Regression and Simple Slopes Analyses}

Hierarchical regression models were tested in SAS 9.3 to examine our hypotheses regarding the moderating effects of fear of compassion from others on the association between self-criticism and depression. Self-criticism (Inadequate Self) and fear of compassion from others were standardized and then entered in the first step of the regression predicting depression. The overall model was significant, $R^{2}=.504, F(2,61)=30.96, p<.001$. Higher levels of depression were predicted by greater self-criticism, $b=4.76, \mathrm{SE}_{b}=1.05, \beta=.46, s r^{2}=$ $.168, t(61)=4.54, p<.001$, and greater fear of compassion from others, $b=3.80, \mathrm{SE}_{b}=1.05, \beta=$ $.37, s r^{2}=.107, t(61)=3.63, p<.001$. The interaction between self-criticism and fear of compassion was then entered in the second step of the regression predicting depression. The overall model was significant, $R^{2}=.575, F(3,60)=27.11, p<.001$, as was the increase in 
explained variance from step 1 to step $2, F(1,60)=10.13, p=.002$. The interaction was significant, $b=2.28, \mathrm{SE}_{b}=0.72, \beta=.22, s r^{2}=.072, t(60)=3.18, p=.002$, indicating that the strength of the relationship between self-criticism and depression depended on the level of fear of compassion from others (see Figure 1a). We probed the interaction by examining the simple slopes for the association between self-criticism and depression at low (-1 SD) and high (+1 SD) levels of fear of compassion. Results showed a significant positive association between selfcriticism and depression only at high fear of compassion from others, $b=6.71, \mathrm{SE}_{b}=1.15, \beta=$ $.65, p<.001$, but no association at low fear of compassion from others, $b=2.14, \mathrm{SE}_{b}=1.28, \beta=$ $.21, p=.10$.

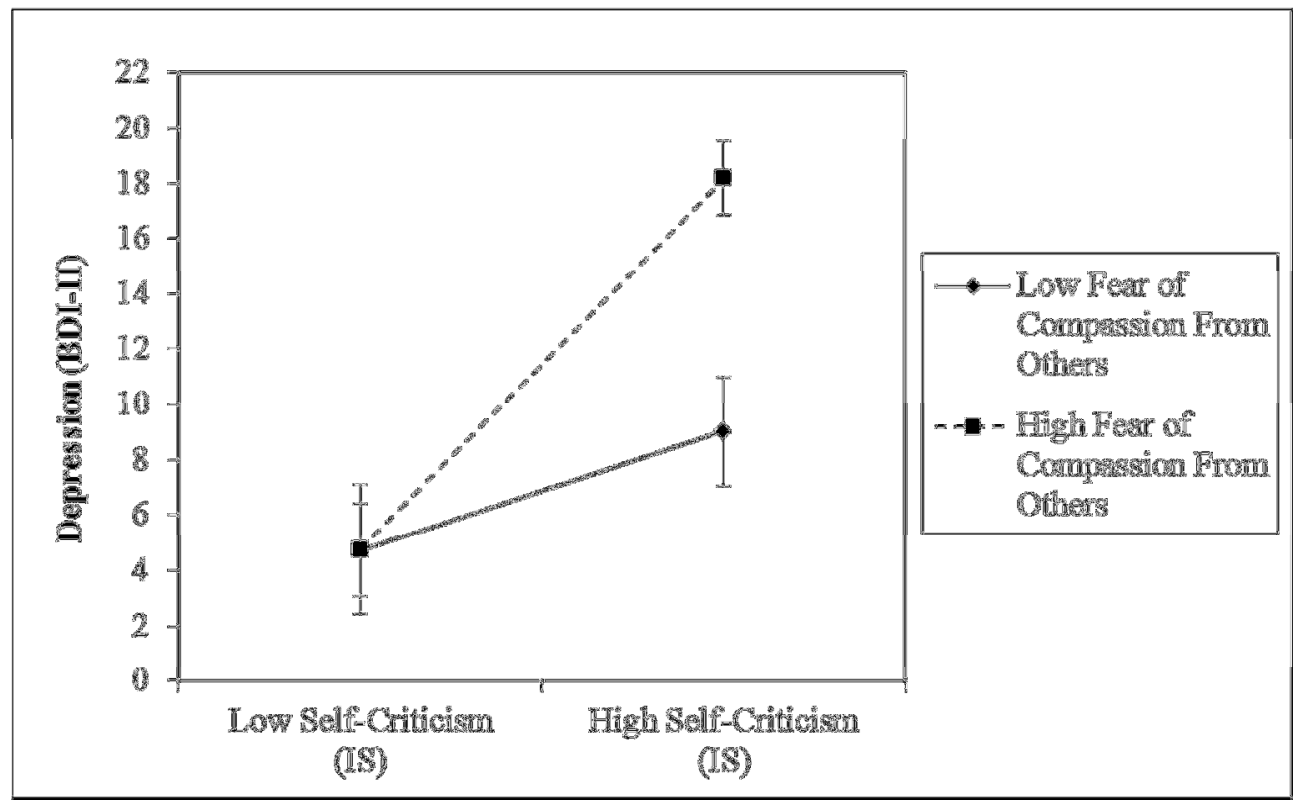

Figure 1a. Relationship between depression and self-criticism with low and high fear of compassion from others $( \pm 1 S D)$ in Montreal, Canada sample of students. Error bars represent standard errors. BDI-II = Beck Depression Inventory-II. IS = Inadequate Self.

We also examined self-criticism as assessed using the DEQ with the same steps outlined above. The overall model was significant, $R^{2}=.418, F(2,61)=21.86, p<.001$. Higher levels of depression were predicted by greater self-criticism, $b=3.50, \mathrm{SE}_{b}=1.20, \beta=.34, s r^{2}=.082, t(61)$ $=2.92, p=.005$, and greater fear of compassion from others, $b=4.11, \mathrm{SE}_{b}=1.20, \beta=.40, s r^{2}=$ 
$.112, t(61)=3.43, p=.001$. The interaction between self-criticism and fear of compassion was then entered in the second step of the regression predicting depression. The overall model was significant, $R^{2}=.473, F(3,60)=17.91, p<.001$, as was the increase in explained variance from step 1 to step $2, F(1,60)=6.26, p=.015$. The interaction was significant, $b=1.73, \mathrm{SE}_{b}=0.69, \beta$ $=.17, s r^{2}=.055, t(60)=2.50, p=.015$, indicating that the strength of the relationship between self-criticism and depression depended on the level of fear of compassion from others (see Figure 1b). Simple slopes analysis showed a significant positive association between selfcriticism and depression only at high fear of compassion from others, $b=4.87, \mathrm{SE}_{b}=1.27, \beta=$ $.47, p<.001$, but no association at low fear of compassion from others, $b=1.42, \mathrm{SE}_{b}=1.42, \beta=$ $.14, p=.32$.

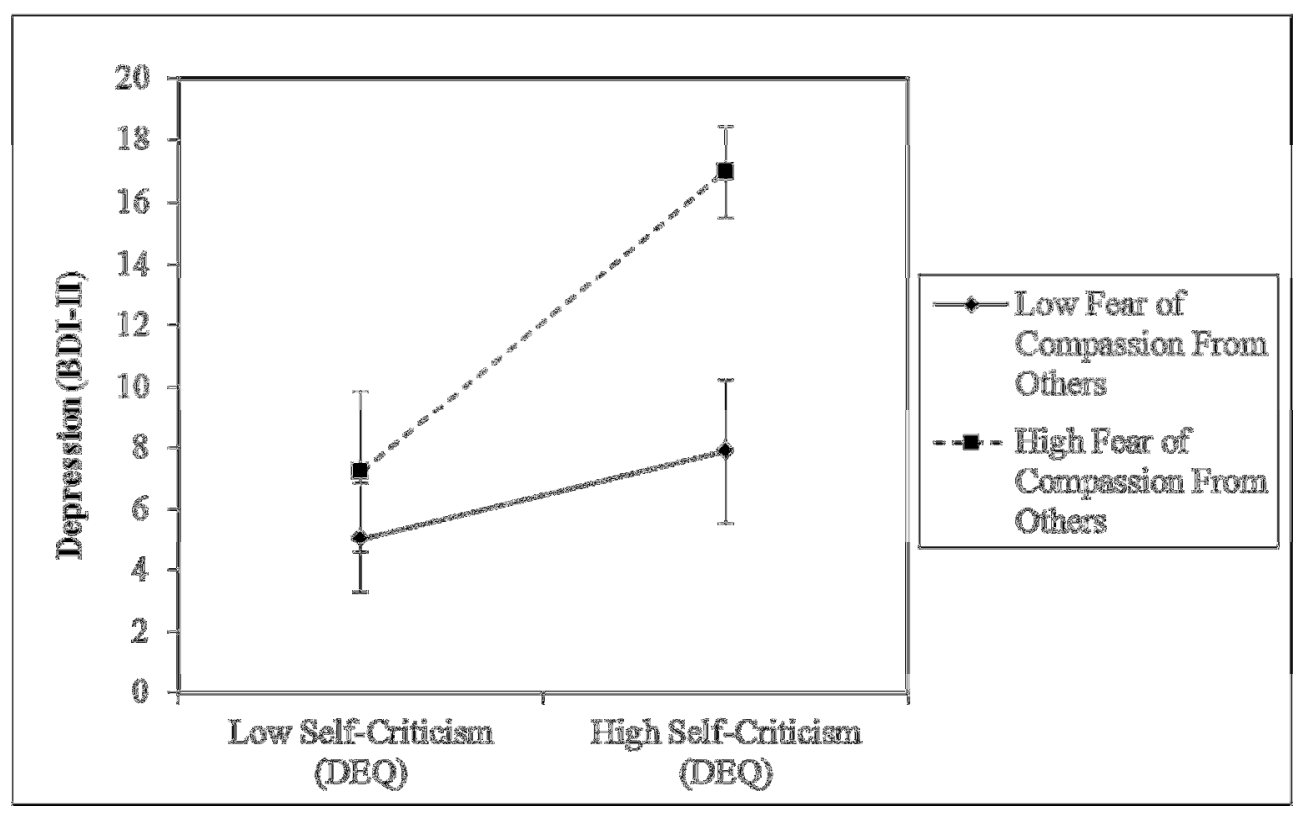

Figure $1 b$. Relationship between depression and self-criticism with low and high fear of compassion from others $( \pm 1 S D)$ in Montreal, Canada sample of students. Error bars represent standard errors. BDI-II = Beck Depression Inventory-II. DEQ $=$ Depressive Experiences Questionnaire.

We also examined potential differences between ethnic backgrounds. Results showed no significant main effect of ethnicity, and no two-way or three-way interactions with ethnicity. 


\section{Study 2 (University Students from Waterloo, Canada)}

\section{Method}

Participants and procedure. Participants were 150 female undergraduate students attending a medium-sized university in Waterloo, Canada ranging in age from 18 to 42 years old $(M=20.29, S D=3.55)$. Participants were of Caucasian background $(48.3 \%)$, South Asian (19.4\%), East Asian (12.9\%), Southeast Asian (6.5\%), Black/African (3.2\%), bi-racial (3.2\%), West Indian/Caribbean (2.6\%), and other (3.9\%). The sample was recruited from the university participant pool with advertisements for a study on personality, feelings, and body image. Participants completed a series of self-report measures online and received half a percent towards their grade in an undergraduate psychology course.

\section{Measures}

Measures of fear of compassion from others (subscale of FOCS), self-criticism (Inadequate Self subscale of FSCRS), and depression (BDI-II) were administered. Cronbach's alphas in this study were $.92, .90$, and .91 respectively. Descriptions of the measures can be found in the Method section of Study 1.

\section{Results}

\section{Descriptive Statistics and Correlations}

Descriptive statistics and correlations are presented in Table 2. Consistent with hypotheses, self-criticism, fear of compassion from others, and depression were positively correlated. 
Table 2. Correlations and descriptive statistics for variables in Study 2 - University students from Waterloo, Canada $(N=150)$

\begin{tabular}{lrrr}
\hline & $\begin{array}{c}\text { Self- } \\
\text { Criticism (IS) }\end{array}$ & $\begin{array}{c}\text { Fear of Compassion } \\
\text { From Others }\end{array}$ & \multicolumn{2}{c}{$\begin{array}{c}\text { Depression } \\
\text { (BDI-II) }\end{array}$} \\
\hline Self-Criticism (IS) & 1 & $.47 *$ & $.59^{*}$ \\
Fear of Compassion & & & \\
From Others & & & $.51^{*}$ \\
Depression (BDI-II) & & 16.56 & 1 \\
\hline Mean & 18.90 & 10.26 & 11.20 \\
SD & 8.12 & 9.45 \\
\hline
\end{tabular}

Note. IS = Inadequate Self. BDI-II = Beck Depression Inventory-II.

$* p<.001$.

\section{Regression and Simple Slopes Analyses}

The same statistical procedures as in Study 1 were used to examine our hypotheses. The overall model was significant, $R^{2}=.415, F(2,146)=51.69, p<.001$. Higher levels of depression were predicted by greater self-criticism, $b=4.20, \mathrm{SE}_{b}=.68, \beta=.45, s r^{2}=.154, t(146)=6.19, p$ $<.001$, and greater fear of compassion from others, $b=2.79, \mathrm{SE}_{b}=.68, \beta=.30, s r^{2}=.067$, $t(146)=4.09, p<.001$. The interaction between self-criticism and fear of compassion was then entered in the second step of the regression predicting depression. The overall model was significant, $R^{2}=.436, F(3,145)=37.35, p<.001$, as was the increase in explained variance from step 1 to step $2, F(1,145)=5.49, p=.021$. The interaction was significant, $b=1.28, \mathrm{SE}_{b}=$ $0.55, \beta=.14, s r^{2}=.021, t(145)=2.34, p=.021$, indicating that the strength of the relationship between self-criticism and depression depended on the level of fear of compassion from others (see Figure 2). Simple slopes analysis showed a significant positive association between selfcriticism and depression at high fear of compassion from others, $b=5.52, \mathrm{SE}_{b}=.87, \beta=.58, p<$ .001 , and a weaker association at low fear of compassion from others, $b=2.96, \mathrm{SE}_{b}=.86, \beta=$ $.31, p=.001$. 


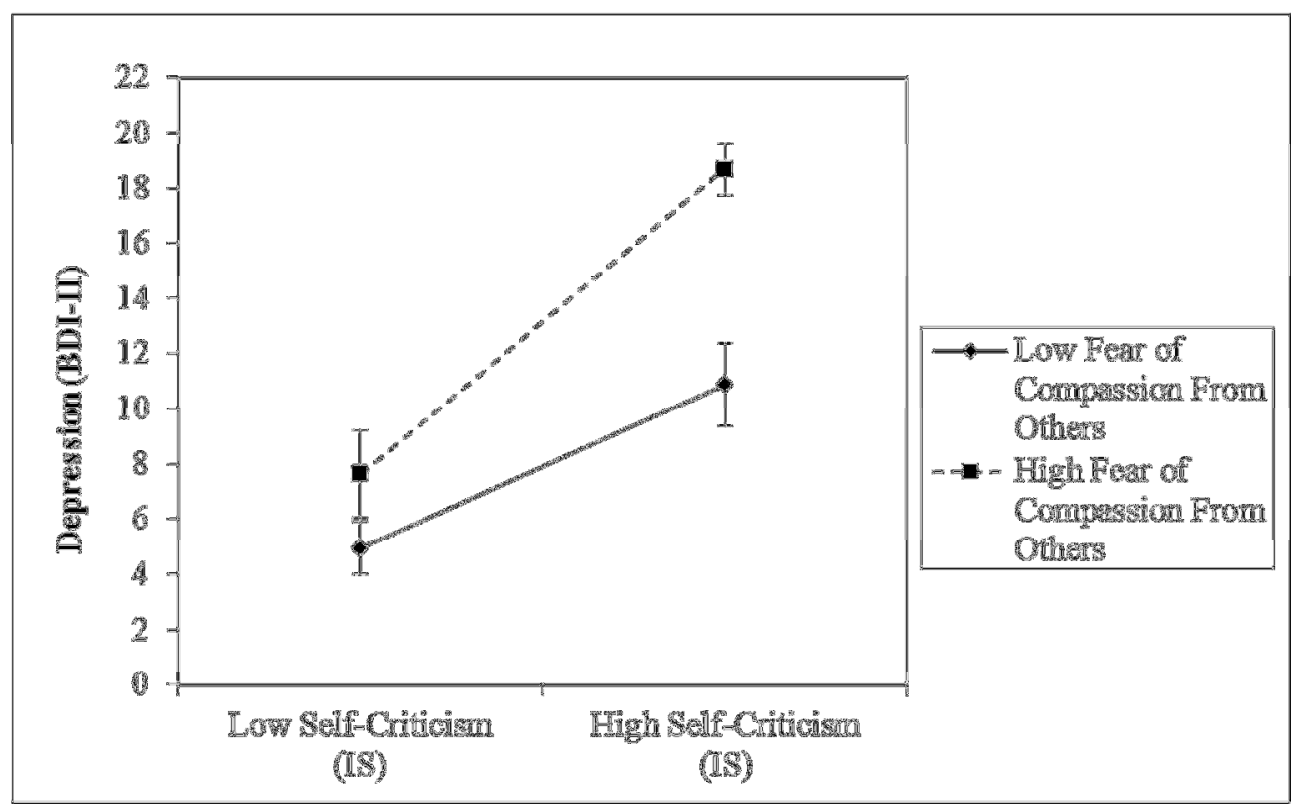

Figure 2. Relationship between depression and self-criticism with low and high fear of compassion from others $( \pm 1 S D)$ in Waterloo, Canada sample of female students. Error bars represent standard errors. BDI-II = Beck Depression Inventory-II. IS = Inadequate Self.

We also examined potential differences between ethnic backgrounds. Results showed no significant main effect of ethnicity, and no two-way or three-way interactions with ethnicity.

\section{Study 3 (University Students from England)}

\section{Method}

Participants and procedure. Participants were 185 students (153 women, 32 men) attending a medium-sized university in England ranging in age from 18 to 57 years old $(M=$ 27.97, $S D=9.80)$. Ethnicity of participants was not assessed. Participants were invited to take part in a study of emotions advertised by research assistants who visited lecture sessions at the university. Participants completed paper questionnaires at home and received course credit.

\section{Measures}

Depressive symptoms. The short-form version of the Depression, Anxiety, and Stress Scales (DASS-21; Lovibond \& Lovibond, 1995) is a set of three subscales assessing symptoms 
of depression, anxiety, and stress. The present study was concerned only with the subscale assessing depression comprising seven items (e.g., "I felt that life was meaningless" and "I felt down-hearted and blue"). Participants rated how much each statement applied to them over the past week on a 4-point Likert scale ranging from 0 (did not apply to me at all) to 3 (applied to me very much, or most of the time). The DASS-21 has good psychometric properties (Henry \& Crawford, 2005). In the current study, Cronbach's alpha was .88.

Measures of fear of compassion from others (subscale of FOCS) and self-criticism (Inadequate Self subscale of FSCRS) were also administered. Cronbach's alphas in this study were .91 and .89 respectively. Descriptions of these measures can be found in the Method section of Study 1.

\section{Results}

\section{Descriptive Statistics and Correlations}

Descriptive statistics and correlations are presented in Table 3. Consistent with hypotheses, self-criticism, fear of compassion from others, and depression were positively correlated. The correlations between these variables in this sample have been previously reported (Gilbert et al., 2012).

Table 3. Correlations and descriptive statistics for variables in Study 3 - University students from England $(N=185)$

\begin{tabular}{lrrr}
\hline & $\begin{array}{c}\text { Self-Criticism } \\
\text { (IS) }\end{array}$ & $\begin{array}{c}\text { Fear of Compassion } \\
\text { From Others }\end{array}$ & \multicolumn{2}{c}{$\begin{array}{c}\text { Depression } \\
\text { (DASS-21) }\end{array}$} \\
\hline Self-Criticism (IS) & 1 & $.47 *$ & $.56^{*}$ \\
Fear of Compassion & & & $.48^{*}$ \\
From Others & & 1 & 1 \\
Depression (DASS-21) & 18.23 & 15.26 & 5.65 \\
Mean & 8.04 & 9.61 & 5.13 \\
SD & & & \\
\hline
\end{tabular}

Note. IS = Inadequate Self. DASS-21 = Depression Anxiety Stress Scales.

$* p<.001$. 


\section{Regression and Simple Slopes Analyses}

The same statistical procedures were used to examine our hypotheses. The overall model was significant, $R^{2}=.376, F(2,182)=54.86, p<.001$. Higher levels of depression were predicted by greater self-criticism, $b=2.19, \mathrm{SE}_{b}=.34, \beta=.43, s r^{2}=.142, t(182)=6.44, p<$ .001 , and greater fear of compassion from others, $b=1.44, \mathrm{SE}_{b}=.34, \beta=.28, s r^{2}=.062, t(182)$ $=4.24, p<.001$. The interaction between self-criticism and fear of compassion was then entered in the second step of the regression predicting depression. The overall model was significant, $R^{2}$ $=.390, F(3,181)=38.51, p<.001$, as was the increase in explained variance from step 1 to step $2, F(1,181)=4.02, p=.047$. The interaction was significant, $b=0.58, \mathrm{SE}_{b}=0.29, \beta=.11, s r^{2}=$ $.014, t(181)=2.00, p=.047$, indicating that the strength of the relationship between selfcriticism and depression depended on the level of fear of compassion from others (see Figure 3). Simple slopes analysis showed a significant positive association between self-criticism and depression at high fear of compassion from others, $b=2.78, \mathrm{SE}_{b}=.45, \beta=.54, p<.001$, and a weaker association at low fear of compassion from others, $b=1.63, \mathrm{SE}_{b}=.44, \beta=.32, p=.003$.

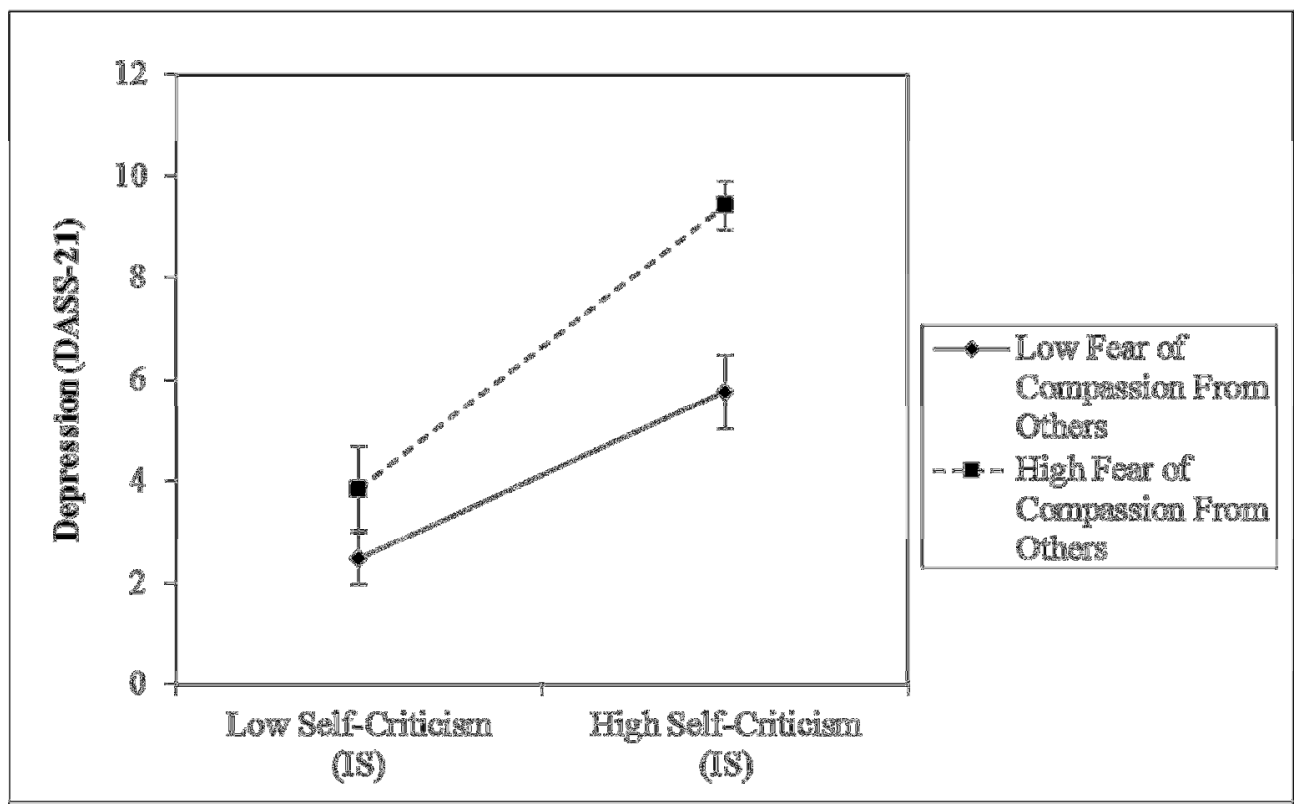


Figure 3. Relationship between depression and self-criticism with low and high fear of compassion from others $( \pm 1 S D)$ in England sample of students. Error bars represent standard errors. DASS-21 = Depression Anxiety Stress Scales. IS = Inadequate Self.

We also examined potential gender differences. Although the sample included a small number of men $(n=32)$, we tested the triple interaction of gender by self-criticism by fear of compassion in predicting depression. The interaction was not significant. Moreover, results remained unchanged when examining the sub-sample of women $(n=153)$ with the men omitted.

\section{Study 4 (Community Adults from Portugal)}

\section{Method}

Participants and procedure. Participants were 302 community adults (131 women, 171 men) living in Portugal ranging in age from 18 to 62 years old $(M=36.28, S D=11.45)$. Ethnicity of participants was not assessed. Participants were employees of several institutions, including schools and private corporations, which were readily accessible to the researchers. Participation in the study was voluntary and participants were not compensated. Participants completed paper questionnaires at home.

\section{Measures}

The following measures were administered in Portuguese. The measures were translated from the original English version and adapted to the Portuguese language following stringent back-translation procedures. These measures have been previously validated in Portuguese samples and revealed sound psychometric properties.

Depressive symptoms. The original 42-item version of the Depression, Anxiety, and Stress Scales (DASS-42; Lovibond \& Lovibond, 1995; Portuguese version by Pais-Ribero, Honrado, \& Leal, 2004) was used. The present study was concerned only with the subscale 
assessing depression which comprised 14 items. The DASS-42 has good psychometric properties (Antony, Bieling, Cox, Enns, \& Swinson, 1998). In the current study, Cronbach's alpha was .96. Measures of fear of compassion from others (subscale of FOCS; Portuguese version by Matos, Pinto-Gouveia, Duarte, \& Simões, 2012) and self-criticism (Inadequate Self subscale of FSCRS; Portuguese version by Castilho \& Pinto-Gouveia, 2011) were also administered.

Cronbach's alphas in this study were .91 and .89 respectively. Descriptions of these measures can be found in the Method section of Study 1.

\section{Results}

\section{Descriptive Statistics and Correlations}

Descriptive statistics and correlations are presented in Table 4. Consistent with hypotheses, self-criticism, fear of compassion from others, and depression were positively correlated.

Table 4. Correlations and descriptive statistics for variables in Study 4 - Community adults from Portugal $(N=302)$

\begin{tabular}{lrrr}
\hline & $\begin{array}{c}\text { Self- } \\
\text { Criticism (IS) }\end{array}$ & $\begin{array}{c}\text { Fear of Compassion } \\
\text { From Others }\end{array}$ & $\begin{array}{c}\text { Depression } \\
\text { (DASS-42) }\end{array}$ \\
\hline Self-Criticism (IS) & 1 & $.39^{*}$ & $.63^{*}$ \\
Fear of Compassion & & & $.48^{*}$ \\
From Others & & 1 & 1 \\
Depression (DASS-42) & 11.31 & 16.57 & 7.05 \\
Mean & 7.00 & 10.32 & 8.19 \\
SD & & & \\
\hline
\end{tabular}

Note. IS = Inadequate Self. DASS = Depression Anxiety Stress Scales.

$* p<.001$.

\section{Regression and Simple Slopes Analyses}

The same statistical procedures were used to examine our hypotheses. The overall model was significant, $R^{2}=.465, F(2,299)=129.67, p<.001$. Higher levels of depression were predicted by greater self-criticism, $b=4.32, \mathrm{SE}_{b}=.38, \beta=.53, s r^{2}=.236, t(299)=11.47, p<$ 
.001 , and greater fear of compassion from others, $b=2.23, \mathrm{SE}_{b}=.38, \beta=.27, s r^{2}=.063, t(299)$ $=5.92, p<.001$. The interaction between self-criticism and fear of compassion was then entered in the second step of the regression predicting depression. The overall model was significant, $R^{2}$ $=.524, F(3,298)=109.26, p<.001$, as was the increase in explained variance from step 1 to step $2, F(1,298)=37.12, p<.001$. The interaction was significant, $b=1.94, \mathrm{SE}_{b}=0.32, \beta=.24$, $s r^{2}=.059, t(298)=6.09, p<.001$, indicating that the strength of the relationship between selfcriticism and depression depended on the level of fear of compassion from others (see Figure 4). Simple slopes analysis showed a significant positive association between self-criticism and depression at high fear of compassion from others, $b=5.99, \mathrm{SE}_{b}=.45, \beta=.73, p<.001$, and a weaker association at low fear of compassion from others, $b=2.10, \mathrm{SE}_{b}=.51, \beta=.26, p<.001$.

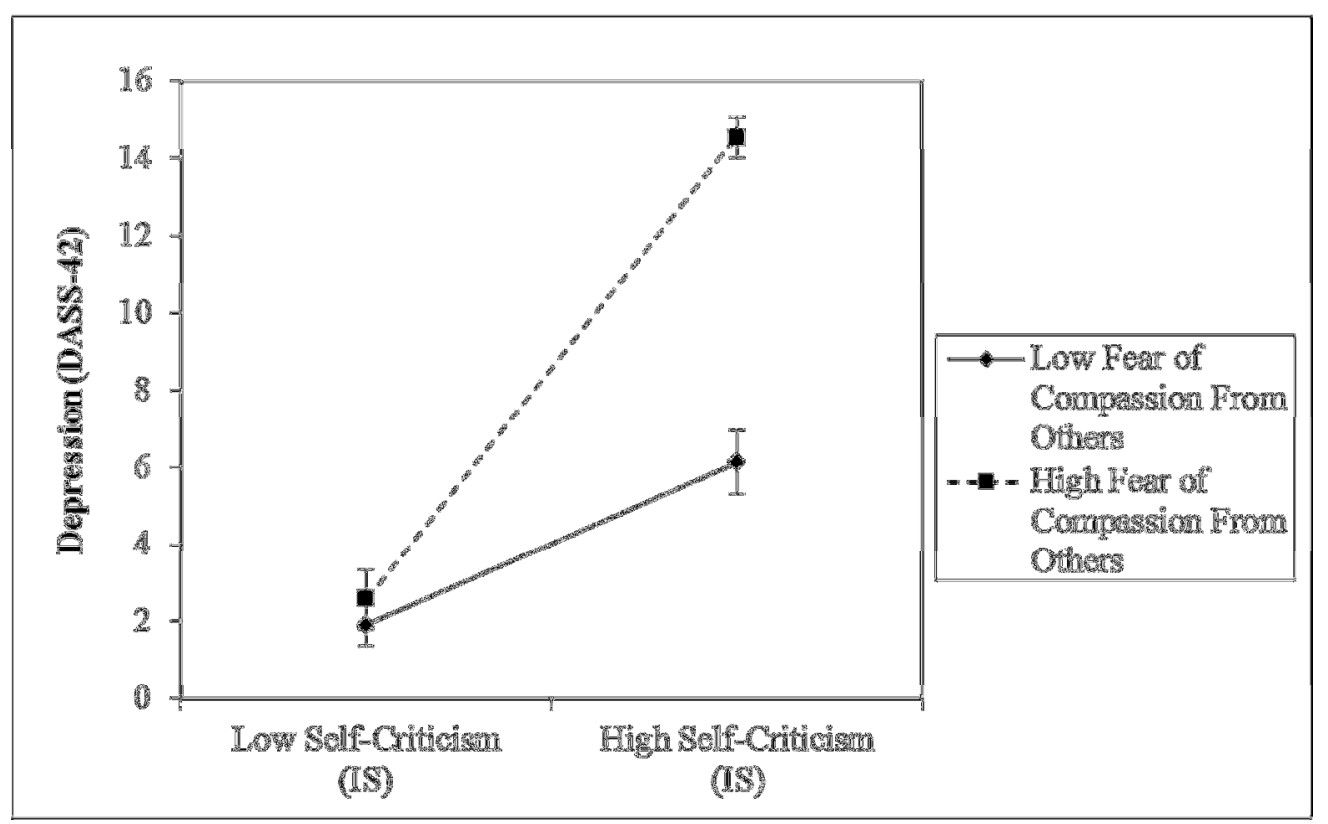

Figure 4. Relationship between depression and self-criticism with low and high fear of compassion from others $( \pm 1 S D)$ in Portugal sample of community adults. Error bars represent standard errors. DASS-42 = Depression Anxiety Stress Scales. IS = Inadequate Self.

We also examined potential gender differences. The triple interaction of gender by selfcriticism by fear of compassion in predicting depression was not significant. 


\section{Meta-Analysis}

We conducted a meta-analysis of the four separate studies to determine the overall effect size of our findings. Effect-size computations and summary analyses were conducted using the meta-analysis program DSTAT (Johnson, 1993). Regression coefficients of the main and moderating effects were converted to Cohen's $d$. Composite effect size estimates $(d+)$ were computed as the average of the individual effects $(d)$ weighted by the reciprocal of their variance, thereby giving greater weight to more reliable effect size estimates (Hedges \& Olkin, 1985). Each calculation of $d+$ provided a test of whether the value differed from zero and a $95 \%$ confidence interval (CI). The homogeneity of the set of effect sizes was tested by the withinclass goodness-of-fit statistic $\left(Q_{w}\right)$, which has an approximate chi-square distribution with $k-1$ degrees of freedom, where $k$ equals the number of effect sizes being assimilated (Johnson, 1993).

First, we examined the overall effect size of the main effects of self-criticism and fear of compassion from the first step of the hierarchical regression. The set of effects was homogeneous for both self-criticism $\left(Q_{w}(3)=4.28, p=.23\right)$ and fear of compassion $\left(Q_{w}(3)=\right.$ $0.78, p=.85$ ), indicating results across studies to be sufficiently similar to warrant their combination into an overall effect. The overall main effect of self-criticism on depression was large in size and highly significant, $d+=1.12, p<.001,95 \%$ CI $[0.96,1.29]$. The overall main effect of fear of compassion on depression was medium in size and highly significant, $d+=0.68$, $p<.001,95 \%$ CI $[0.53,0.84]$. Second, we examined the overall effect size of the moderating effect from the second step of the hierarchical regression. The set of effects was homogeneous $\left(Q_{w}(3)=5.65, p=.13\right)$. The overall moderating effect of fear of compassion on the relationship between self-criticism and depression was medium in size and highly significant, $d+=0.53, p<$ 
$.001,95 \% \mathrm{CI}[0.37,0.68]$. In sum, the main effects of self-criticism and fear of compassion and their interaction effect in predicting depression are consistent and robust across our four studies.

\section{General Discussion}

Across four samples, self-criticism, fear of compassion from others, and depression were all positively correlated in accordance with our hypothesis. Additionally, there were main effects of self-criticism and fear of compassion in predicting higher levels of depression. Meta-analytic results showed the overall main effects were large in size for self-criticism and medium in size for fear of compassion. This is consistent with the extensive body of literature showing the depressogenic effect of self-criticism (Blatt \& Zuroff, 1992), and the growing research in fear of compassion as a factor implicated in psychopathology (Gilbert et al., 2011, 2012).

Our primary aim was to investigate the moderating effect of fear of receiving compassion on the association between self-criticism and depression. Results supported our hypothesis that self-criticism and depression are positively related, but that the effect is strengthened for individuals who are high on fear of receiving compassion from others, and weakened for individuals who are low on fear of compassion. Therefore, being open and receptive to care, warmth, and kindness from others may buffer the depressogenic effect of self-criticism, while being uncomfortable or fearful of compassion from others exacerbates this effect. That this moderating effect was replicated across four samples that range in age (students and community adults), geographical and cultural contexts (a large multi-cultural city in Canada, a mid-sized city in Canada, England, and Portugal), as well as two different measures of self-criticism and depression, suggests it to be a robust phenomenon. The consistency of these findings is even more impressive when considering the aggregate effect computed across studies was medium in size and highly significant. 
The threatening early histories and the ongoing internal hostility experienced by selfcritical individuals suggest that they possess an over-developed and chronically activated threat system. Indeed, self-critics have been shown to experience high levels of negative affect. Moreover, their fearful avoidant attachment style and self-protective interpersonal behaviours suggest that they minimally receive signals of security and support needed to stimulate the soothing system, and indeed self-critics have been shown to experience low levels of social safeness. Therefore, the combination of being highly self-critical and highly fearful of compassion means having an over-activated threat system and under-activated soothing system, which constitutes a dual vulnerability to depression. This is consistent with our findings that show a stronger relationship between self-criticism and depression for those fearful of compassion. However, if self-critics are able to attune to signals of care and internalize compassion from others, the soothing system will be activated and may serve to down-regulate the threat system. Our results show that the relationship between self-criticism and depression is weaker for individuals low in fear of compassion.

Our findings indicate that highly self-critical individuals who are low in fear of compassion experience less depression than their self-critical peers who are fearful of compassion. Thus, there appears to be a subgroup of self-critics who are able to receive care and support from others. This raises the question of whether there are perhaps less maladaptive forms of self-criticism. Thompson and Zuroff (2004) have differentiated between two types of selfcriticism termed comparative self-criticism and internalized self-criticism. Comparative selfcriticism is a negative view of self in comparison to others who are seen as superior and threatening, whereas internalized self-criticism is a negative view of self based on one's own high personal standards. Comparative self-criticism is uniquely negatively associated with secure 
attachment and positively associated with fearful avoidant attachment, while internalized selfcriticism is not related to attachment issues (Thompson \& Zuroff, 2004). Furthermore, psychological distress is more strongly related to comparative self-criticism than internalized self-criticism (Thompson \& Zuroff, 2004), suggesting the internalized type of self-criticism to be less maladaptive.

As forms of self-derogation, shame and guilt are constructs related to self-criticism. Shame is viewed as a global negative self-evaluation in which one's character is seen as flawed, while guilt is more specifically focused on a controllable source of self-blame, such as the offensive behaviour or failure in question (Tangney, 1990). Shame is associated with high fears of intimacy (Lutwak, Panish, \& Ferrari, 2003) as well as depression (Tangney, Wagner, \& Gramzow, 1992), while guilt is not related to either (Lutwak et al., 2003; Tangney et al., 1992). The extent to which self-critics experience shame or guilt is expected to influence their likelihood to avoid others or to move towards others for care and support during times of distress; thus, moderating levels of depression accordingly. Integrating the research on forms of self-derogation (shame and guilt) and forms of self-criticism (comparative and internalized), the self-critics observed in our study who were low in fear of compassion and protected from depression may be those who experience guilt and hold internalized standards.

Our findings may have clinical implications for working with self-critical individuals struggling with depression. Self-criticism is a relatively stable personality style (Zuroff et al., 2004) that is difficult to target directly in therapy (Gilbert, 2009; Gilbert \& Procter, 2006). However, the fear of receiving compassion (i.e., an affiliative emotion) may be more amenable to change using traditional techniques such as gradual exposure and desensitization to feared stimuli (e.g., Abramowitz, Deacon, \& Whiteside, 2012). Compassion focused therapy (CFT; 
Gilbert, 2009) was developed for people struggling with high levels of shame and self-criticism. The CFT approach includes imagery exposure exercises of receiving compassion from an "ideal compassionate figure", as well as in vivo exposure exercises to encourage affiliative relationships and receiving care and kindness from close others. In a randomized controlled trial, compassion cultivation training decreased the fear of compassion from others (Jazaieri et al., 2013), suggesting that fear of compassion is a viable therapeutic target that is amenable to change. Widely-practiced therapies for depression, such as cognitive-behavioural therapy, focus on challenging negative thoughts and performing activating behaviours. However, depressive symptoms may also be effectively targeted with interventions that help patients become more comfortable showing vulnerability in their important relationships and to become more receptive to feeling soothed and cared for.

Integrating the psychotherapy literature on self-criticism (for reviews, see Kannan \& Levitt, 2013; Kelly \& Zuroff, 2013), our findings suggest the importance of helping self-critical patients experience and internalize compassion from the therapist. A patient's relational ability depends on mental representations that have mainly developed in the context of early experiences, but can be modified through corrective emotional experiences afforded in psychotherapy (Blatt, Auerbach, \& Levy, 1997). The negative mental representations held by self-critics can obscure their ability to experience warmth, empathy, and support from the therapist (Zuroff, Shahar, Blatt, Kelly, \& Leybman, 2016). Self-critical patients may expect criticism or neglect from the therapist and defensively withdraw from the therapeutic relationship. Thus, therapists should anticipate and appropriately manage ruptures in the alliance with patience, persistence, and compassion (Shahar, 2015). 


\section{Limitations}

Although our findings appear to be robust, several limitations should be acknowledged. First, the present results are limited by their reliance on cross-sectional data that precludes conclusions about causality and directionality. We cannot conclude whether self-criticism and fear of compassion together leads to depression or vice versa. Future research using longitudinal or prospective designs would enhance our findings and allow for an examination of the potential mediating roles of affect regulation systems, experiences of shame and guilt, and/or mental representations. Second, our samples consisted primarily of women. Given that women are more likely than men to experience depression (Nolem-Hoeksema, 1990) and to be more comfortable seeking emotional support from others (Tamres, Janicki, \& Helgeson, 2002), it is important to investigate the effects of gender. Of the four samples, only the Portuguese community adults sample (Study 4) had an adequate number of men to allow for testing of gender differences. Although no gender effects were found, future studies should aim to recruit adequate numbers of men and women to clarify potential gender differences. Finally, because results are based on data from students and community adults, the findings may not be generalizable to clinical populations. Future research should consider examining clinically depressed patients or remitted depressed patients, for which these findings have the most clinical utility.

\section{Conclusion}

In conclusion, the well-documented positive association between self-criticism and depression is moderated by the fear of receiving compassion from others. High fear of receiving compassion strengthens the relationship between self-criticism and depression, whereas low fear of compassion weakens the relationship. This phenomenon was evident across four diverse samples varying in age (students and community adults), geographical and cultural context 
(Canada, England, and Portugal), as well as across two different measures of self-criticism and depression. Findings suggest that helping self-critical individuals become more comfortable receiving compassion from others may buffer the depressogenic effect of self-criticism. 


\section{References}

Abramowitz, J. S., Deacon, B. J., \& Whiteside, S. P. (2012). Exposure therapy for anxiety: Principles and practice. New York, NY: Guilford Press.

Antony, M. M., Bieling, P. J., Cox, B. J., Enns, M. W., \& Swinson, R. P. (1998). Psychometric properties of the 42-item and 21-item versions of the Depression Anxiety Stress Scales in clinical groups and a community sample. Psychological Assessment, 10(2), 176-181. doi: $10.1037 / 1040-3590.10 .2 .176$

Baldwin, M. W. (1992). Relational schemas and the processing of social information. Psychological Bulletin, 112, 461- 484. doi:10.1037/0033-2909.112.3.461

Beck, A. T., Steer, R. A., \& Brown, G. K. (1996). Beck Depression Inventory - Second Edition Manual. San Antonio, TX: Psychological Corporation.

Billings, A. G., \& Moos, R. H. (1985). Life stressors and social resources affect posttreatment outcomes among depressed patients. Journal of Abnormal Psychology, 94(2), 140-153. doi: 10.1037/0021-843X.94.2.140

Blatt, S. J. (1974). Levels of object representation in anaclitic and introjective depression. Psychoanalytic Study of the Child, 29(10), 107-157.

Blatt, S. J. (2004). Experiences of depression: Theoretical, clinical, and research perspectives. Washington, DC: American Psychological Association.

Blatt, S. J., Auerbach, J. S., \& Levy, K. N. (1997). Mental representations in personality development, psychopathology, and the therapeutic process. Review of General Psychology, 1(4), 351-374. doi: 10.1037/1089-2680.1.4.351 
Blatt, S. J., D’Afflitti, J. P., \& Quinlan, D. M. (1976). Experiences of depression in normal young adults. Journal of Abnormal Psychology, 85, 383-389. doi:10.1037/0021$843 X .85 .4 .383$

Blatt, S. J., \& Homann, E. (1992). Parent-child interaction in the etiology of dependent and selfcritical depression. Clinical Psychology Review, 12(1), 47-91. doi:10.1016/02727358(92)90091-L

Blatt, S. J., Quinlan, D. M., Pilkonis, P. A., \& Shea, M. T. (1995). Impact of perfectionism and need for approval on the brief treatment of depression: the National Institute of Mental Health Treatment of Depression Collaborative Research Program revisited. Journal of Consulting and Clinical Psychology, 63(1), 125-132. doi: 10.1037/0022-006X.63.3.494

Blatt, S. J., \& Zuroff, D. C. (1992). Interpersonal relatedness and self-definition: Two prototypes for depression. Clinical Psychology Review, 12(5), 527-562. doi: 10.1016/02727358(92)90070-O

Blatt, S. J., \& Zuroff, D. C. (2005). Empirical evaluation of the assumptions in identifying evidence based treatments in mental health. Clinical Psychology Review, 25(4), 459-486. doi: doi:10.1016/j.cpr.2005.03.001

Bowlby, J. (1969/1982). Attachment and loss: Vol. 1. Attachment (2nd ed.). New York, NY: Basic Books.

Castilho, P., \& Gouveia, J. P. (2011). Auto-Criticismo: estudo de validação da versão portuguesa da Escala das Formas do Auto-Criticismo e Auto-Tranquilização (FSCRS) e da Escala das Funções do Auto-Criticismo e Auto-Ataque (FSCS). [Self-Criticism: Validation study of the Portuguese version of the Forms of Self-Criticism and Self-Reassuring Scale (FSCRS) and the Functions of Self-Criticism (FSCS)]. Psychologica, 54, 63-86. 
Dunkley, D. M., Zuroff, D. C., \& Blankstein, K. R. (2003). Self-critical perfectionism and daily affect: Dispositional and situational influences on stress and coping. Journal of Personality and Social Psychology, 84(1), 234-252. doi: 10.1037/0022-3514.84.1.234

George, L. K., Blazer, D. G., Hughes, D. C., \& Fowler, N. (1989). Social support and the outcome of major depression. The British Journal of Psychiatry, 154(4), 478-485. doi: 10.1192/bjp.154.4.478

Gilbert, P. (2005). Compassion and cruelty: A biopsychosocial approach. In P. Gilbert (Ed.), Compassion: Conceptualisations, research and use in psychotherapy (pp. 9-74). London, UK: Brunner-Routledge.

Gilbert, P. (2006). Evolution and depression: Issues and implications. Psychological Medicine, 36(3), 287-297. doi: :10.1017/S0033291705006112

Gilbert, P. (2009). Introducing compassion-focused therapy. Advances in Psychiatric Treatment, 15(3), 199-208. doi: 10.1192/apt.bp.107.005264

Gilbert, P., Clarke, M., Hempel, S., Miles, J. N. V., \& Irons, C. (2004). Criticizing and reassuring oneself: An exploration of forms, styles and reasons in female students. British Journal of Clinical Psychology, 43(1), 31-50. doi:10.1348/014466504772812959

Gilbert, P. \& Irons, C. (2005). Focused therapies and compassionate mind training for shame and self-attacking. In P. Gilbert (Ed.), Compassion: Conceptualisations, research and use in psychotherapy (pp. 263-325). London, UK: Brunner-Routledge.

Gilbert, P., McEwan, K., Catarino, F., \& Baião, R. (2014). Fears of compassion in a depressed population: Implication for psychotherapy. Journal of Depression and Anxiety, S2:003. doi: 10.4172/2167-1044.S2-003

Gilbert, P., McEwan, K., Gibbons, L., Chotai, S., Duarte, J., \& Matos, M. (2012). Fears of 
compassion and happiness in relation to alexithymia, mindfulness, and self-criticism. Psychology and Psychotherapy: Theory, Research and Practice, 85(4), 374-390. doi: 10.1111/j.2044-8341.2011.02046.x

Gilbert, P., McEwan, K., Irons, C., Bhundia, R., Christie, R., Broomhead, C., \& Rockliff, H. (2010). Self-harm in a mixed clinical population: The roles of self-criticism, shame, and social rank. British Journal of Clinical Psychology, 49(4), 563-576. doi: $10.1348 / 014466509 X 479771$

Gilbert, P., McEwan, K., Matos, M., \& Rivis, A. (2011). Fears of compassion: Development of three self-report measures. Psychology and Psychotherapy: Theory, Research and Practice, 84(3), 239-255. doi: :10.1348/147608310X526511

Gilbert, P., \& Procter, S. (2006). Compassionate mind training for people with high shame and self-criticism: Overview and pilot study of a group therapy approach. Clinical Psychology and Psychotherapy, 13(6), 353-379. doi: 10.1002/cpp.507

Hedges, L. V., \& Olkin, I. (1985). Statistical methods for meta-analysis. Orlando, FL: Academic Press.

Hirschfeld, R. M., \& Cross, C. K. (1983). Personality, life events, and social factors in depression. Psychiatry Update: The American Psychiatric Association Annual Review, 2, $382-406$.

Jazaieri, H., Jinpa, G. T., McGonigal, K., Rosenberg, E. L., Finkelstein, J., Simon-Thomas, E., ... Goldin, P. R. (2013). Enhancing compassion: A randomized controlled trial of a compassion cultivation training program. Journal of Happiness Studies, 14(4), 1113-1126. doi: $10.1007 / \mathrm{s} 10902-012-9373-\mathrm{Z}$

Johnson, B. T. (1993). DSTAT 1.10: Software for the meta-analytic review of literatures. 
[Computer software and manual]. Hillsdale, NJ: Erlbaum.

Kannan, D., \& Levitt, H. M. (2013). A review of client self-criticism in psychotherapy. Journal of Psychotherapy Integration, 23(2), 166-178. doi: 10.1037/a0032355

Kelly, A. C., \& Zuroff, D. C. (2013). Perfectionism. In L. Grossman \& S. Walfish (Eds.), Translating psychological research into practice (pp. 233-240). New York, NY: Springer Publishing Company.

Kelly, A. C., Zuroff, D. C., Leybman, M. J., \& Gilbert, P. (2012). Social safeness, received social support, and maladjustment: Testing a tripartite model of affect regulation. Cognitive Therapy and Research, 36(6), 815-826. doi: 10.1007/s10608-011-9432-5

Kernberg, O. F. (1976). Object relations theory and clinical psychoanalysis. New York, NY: Aronson.

Kopala-Sibley, D. C., \& Zuroff, D. C. (2014). The developmental origins of personality factors from the self-definitional and relatedness domains: A review of theory and research. Review of General Psychology, 18(3), 137-155. doi: 10.1037/gpr0000013

Kopala-Sibley, D. C., Zuroff, D. C., Hermanto, N., \& Joyal-Desmarais, K. (2015). The development of self-definition and relatedness in emerging adulthood and their role in the development of depressive symptoms. International Journal of Behavioral Development. doi: $10.1177 / 0165025415573640$

Longe, O., Maratos, F. A., Gilbert, P., Evans, G., Volker, F., Rockliff, H., \& Rippon, G. (2010). Having a word with yourself: Neural correlates of self-criticism and self-reassurance. NeuroImage, 49(2), 1849-1856. doi: 10.1016/j.neuroimage.2009.09.019

Lovibond, S. H., \& Lovibond, P. F. (1995). Manual for the Depression Anxiety Stress Scales. Sydney: Psychology Foundation. 
Lutwak, N., Panish, J., \& Ferrari, J. (2003). Shame and guilt: Characterological vs. behavioral self-blame and their relationship to fear of intimacy. Personality and Individual Differences, 35(4), 909-916. doi:10.1016/S0191-8869(02)00307-0

Matos, M., Pinto-Gouveia, J., Duarte, J., \& Simões, D. (2012). The Portuguese version of the Fears of Compassion Scales. Unpublished manuscript.

Mongrain, M. (1998). Parental representations and support-seeking behaviors related to Dependency and Self-Criticism. Journal of Personality, 66(2), 151-173. doi: $10.1111 / 1467-6494.00007$

Mongrain, M., \& Zuroff, D. C. (1995). Motivational and affective correlates of dependency and self-criticism. Personality and Individual Differences, 18(3), 347-354. doi: 10.1016/01918869(94)00139-J

Nolen-Hoeksema, S. (1990). Sex differences in depression. Stanford, CA: Stanford University Press.

Priel, B., \& Shahar, G. (2000). Dependency, self-criticism, social context and distress: Comparing moderating and mediating models. Personality and Individual Differences, 28(3), 515-525. doi: 10.1016/S0191-8869(99)00116-6

Rector, N. A., Bagby, R. M., Segal, Z. V., Joffe, R. T., \& Levitt, A. (2000). Self-criticism and dependency in depressed patients treated with cognitive therapy or pharmacotherapy. Cognitive Therapy and Research, 24(5), 571-584. doi: 10.1023/A:1005566112869

Ribeiro, J. L. P., Honrado, A. A. J. D., \& Leal, I. P. (2004). Contribuição para o estudo da adaptação portuguesa das escalas de ansiedade, depressão e stress (EADS) de 21 itens de Lovibond e Lovibond. [Contribution to the study of the Portuguese adaption of the 
Lovibond and Lovibond Depression Anxiety Stress Scales (DASS) with 21 items]. Psicologia, Saúde \& Doenças, 5(2), 229-239.

Rockliff, H., Gilbert, P., McEwan, K., Lightman, S., \& Glover, D. (2008). A pilot exploration of heart rate variability and salivary cortisol responses to compassion-focused imagery. Journal of Clinical Neuropsychiatry, 5, 132-139.

Shahar, G. (2015). Erosion: The psychopathology of self-criticism. New York, NY: Oxford University Press.

Steer, R. A., Ball, R., Ranieri, W. F., \& Beck, A. T. (1997). Further evidence for the construct validity of the Beck Depression Inventory-II with psychiatric outpatients. Psychological Reports, 80(2), 443-446. doi: 10.2466/pr0.1997.80.2.443

Tamres, L. K., Janicki, D., \& Helgeson, V. S. (2002). Sex differences in coping behavior: A meta-analytic review and examination of relative coping. Personality and Social Psychology Review, 6(1), 2-30. doi: 10.1207/S15327957PSPR0601_1

Tangney, J. P. (1990). Assessing individual differences in proneness to shame and guilt: Development of the Self-Conscious Affect and Attribution Inventory. Journal of Personality and Social Psychology, 59(1), 102-111. doi: 10.1037/0022-3514.59.1.102

Tangney, J. P., Wagner, P., \& Gramzow, R. (1992). Proneness to shame, proneness to guilt, and psychopathology. Journal of Abnormal Psychology,101(3), 469-478. doi: 10.1037/0021843X.101.3.469

Teasdale, J. D., \& Cox, S. G. (2001). Dysphoria: Self-devaluative and affective components in recovered depressed patients and never depressed controls. Psychological Medicine, 31(7), 1311-1316. doi: 10.1017/S003329170100424X 
Thompson, R., \& Zuroff, D. C. (2004). The Levels of Self-Criticism Scale: Comparative selfcriticism and internalized self-criticism. Personality and Individual Differences, 36(2), 419-430. doi:10.1016/S0191-8869(03)00106-5

Wang, X., Cai, L., Qian, J., \& Peng, J. (2014). Social support moderates stress effects on depression. International Journal of Mental Health Systems, 8(1), 1-5. doi: 10.1186/1752$4458-8-41$

Whelton, W. J., \& Greenberg, L. S. (2005). Emotion in self-criticism. Personality and Individual Differences, 38(7), 1583-1595. doi: 10.1016/j.paid.2004.09.024

Zuroff, D. C., \& Fitzpatrick, D. K. (1995). Depressive personality styles: Implications for adult attachment. Personality and Individual Differences, 18(2), 253-265. doi: 10.1016/01918869(94)00136-G

Zuroff, D. C., Mongrain, M., \& Santor, D. A. (2004). Conceptualizing and measuring personality vulnerability to depression: Comment on Coyne and Whiffen (1995). Psychological Bulletin, 130(3), 489-511. doi: 10.1037/0033-2909.130.3.489

Zuroff, D. C., Santor, D. A., \& Mongrain, M. (2005). Dependency, self-criticism, and maladjustment. In J. S. Auerbach, K. J. Levy, \& C. E. Schaffer (Eds.), Relatedness, selfdefinition and mental representation: Essays in honor of Sidney J. Blatt. London, UK: Brunner-Routledge.

Zuroff, D. C., Shahar, G., Blatt, S. J., Kelly, A. C., \& Leybman, M. (2016). Predictors and moderators of between-therapists and within-therapist differences in depressed outpatients' experiences of the Rogerian conditions. Journal of Counselling Psychology, 63(2), 162172. doi: $10.1037 /$ cou0000139 